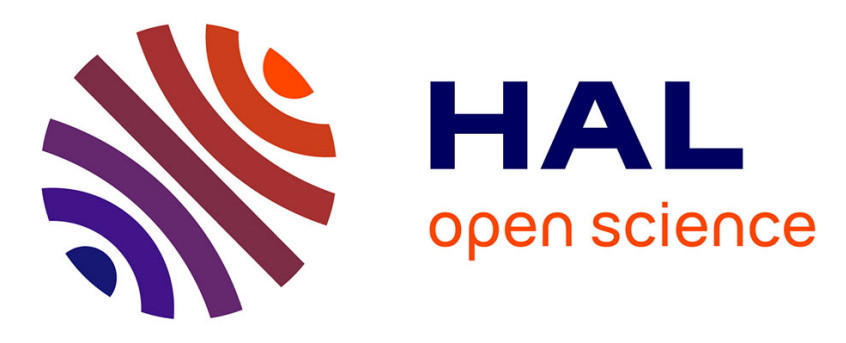

\title{
Density modulated whistler mode emissions observed near the plasmapause
}

\author{
O. Moullard, A. Masson, H Laakso, Michel Parrot, Pierrette Décréau, Ondřej \\ Santolík, M. André
}

\section{- To cite this version:}

O. Moullard, A. Masson, H Laakso, Michel Parrot, Pierrette Décréau, et al.. Density modulated whistler mode emissions observed near the plasmapause. Geophysical Research Letters, 2002, 17, pp.1861 - 1861. insu-01558789

\section{HAL Id: insu-01558789 \\ https://hal-insu.archives-ouvertes.fr/insu-01558789}

Submitted on 10 Jul 2017

HAL is a multi-disciplinary open access archive for the deposit and dissemination of scientific research documents, whether they are published or not. The documents may come from teaching and research institutions in France or abroad, or from public or private research centers.
L'archive ouverte pluridisciplinaire HAL, est destinée au dépôt et à la diffusion de documents scientifiques de niveau recherche, publiés ou non, émanant des établissements d'enseignement et de recherche français ou étrangers, des laboratoires publics ou privés. 


\title{
Density modulated whistler mode emissions observed near the plasmapause
}

\author{
O. Moullard, A. Masson, and H. Laakso \\ RSSD of ESA, ESTEC, Noordwijk, The Netherlands \\ M. Parrot and P. Décréau \\ LPCE, CNRS and University of Orléans, Orléans, France \\ O. Santolik \\ KEVF-MFF, Charles University, Praha, Czech Republic
}

\author{
M. Andre \\ IRF, Uppsala, Sweden
}

Received 11 March 2002; revised 19 June 2002; accepted 19 July 2002; published 25 October 2002.

[1] Electron density fluctuations are regularly observed near the plasmapause together with electromagnetic waves below the electron cyclotron frequency (usually called hiss or chorus). Instruments on board CLUSTER spacecraft often observe two such emission bands with fluctuating wave intensities that suggest wave ducting in density enhancements as well as troughs. Near perigee the CLUSTER density measurements are usually limited to the electron density from 0.2 to $80 \mathrm{~cm}^{-3}$. To establish a correlation between density and wave intensity deeper inside the outer plasmasphere, we extrapolate the electron density from the spacecraft potential after fitting a relationship between observed plasma frequency and spacecraft potential. During a plasmapause crossing on June 5, 2001 (near the geomagnetic equator, $L=4-6$, afternoon sector), density fluctuations up to hundreds $\mathrm{cm}^{-3}$ are found while whistler mode waves are observed in two separate frequency bands, at $100-500 \mathrm{~Hz}$ (correlated to the density fluctuations) and $3-6 \mathrm{kHz}$ (anti-correlated). INDEX TERMS: 2772 Magnetospheric Physics: Plasma waves and instabilities; 2768 Magnetospheric Physics: Plasmasphere; 7853 Space Plasma Physics: Spacecraft/ atmosphere interactions. Citation: Moullard, O., A. Masson, H. Laakso, M. Parrot, P. Décréau, O. Santolik, and M. Andre, Density modulated whistler mode emissions observed near the plasmapause, Geophys. Res. Lett., 29(20), 1975, doi:10.1029/ 2002GL015101, 2002.

\section{Introduction}

[2] The plasmapause is the geomagnetic field-aligned outer boundary of the Earth co-rotating plasmasphere, where the density decreases from typically hundreds or thousands down to a few $\mathrm{cm}^{-3}$ (electron temperature is a few $\mathrm{eV}$ ). The plasmapause is relatively thin and located at around 3-8 L-shells depending on the geomagnetic activity [Carpenter and Lemaire, 1997]. At the flow separatrix, plasma drift changes from co-rotation into convection of a moderately warm $(100-1000 \mathrm{eV})$ magnetospheric plasma driven by

Copyright 2002 by the American Geophysical Union. 0094-8276/02/2002GL015101 solar wind dependent electric fields [Lemaire and Gringauz, 1998]. Velocity shear between opposite flows are expected to cause the formation of plasmaspheric outer layers and detached bubbles. Irregular plasma refilling of flux tubes also follows after disturbed geomagnetic activity. Consequently density profiles measured in-situ show large fluctuations instead of a smooth density gradient [Carpenter et al., 1993].

[3] A variety of whistler mode emissions have been observed in the vicinity of the plasmapause; their origin and propagation mechanisms are still debated. For example, plasmaspheric hiss, a diffuse emission with frequency $f \sim$ $0.3-1 \mathrm{kHz}$, may come from magnetospherically reflected ligthning whistlers amplified during equatorial crossing(s) by gyroresonance with radiation belt electrons or originate from a source near the equator [Lemaire and Gringauz, 1998].

[4] Using data from the CLUSTER spacecraft near perigee (within 15 degrees of the geomagnetic equator, at $\mathrm{L} \sim$ 4 , afternoon sector), we observe two electromagnetic wideband emissions with $f<f_{c_{e}}$ (electron cyclotron frequency $f_{c_{e}} \sim 12 \mathrm{kHz}$ ). Electric field wave data in the frequency range $2-80 \mathrm{kHz}$ are provided by the WHISPER resonance sounder [Décréau et al., 1997] and electric and magnetic spectra below $4 \mathrm{kHz}$ by the STAFF experiment [CornilleauWehrlin et al., 1997]. Both emission bands appear diffuse. One of them, at $f \sim 100-500 \mathrm{~Hz}$, would qualify as plasmaspheric hiss, except for the fact that it is resolved as whistler mode dispersive structures (hence chorus like) by the WBD instrument [Gurnett et al., 1997] over shorter time periods. The other emission band, at $f \sim 3-6 \mathrm{kHz}$, continuous in appearance, could be a long series of shortlived wideband electromagnetic bursts such as observed with DE-1 just outside the plasmapause [Sonwalkar et al., 1990], sometimes accompanied with a $1 \mathrm{kHz}$ hiss emission.

[5] These two types of whistler emission are often observed by the four CLUSTER spacecraft. We show how their fluctuating wave intensities correlate with the large scale density fluctuations found during an example plasmapause crossing, on June 5, 2001. One issue concerns the ducting of whistler waves. Field aligned density enhancements have been favored by observation as good whistlers ducts yet ducting in troughs is also possible in theory [Angerami, 1970; Koons, 1989]. 

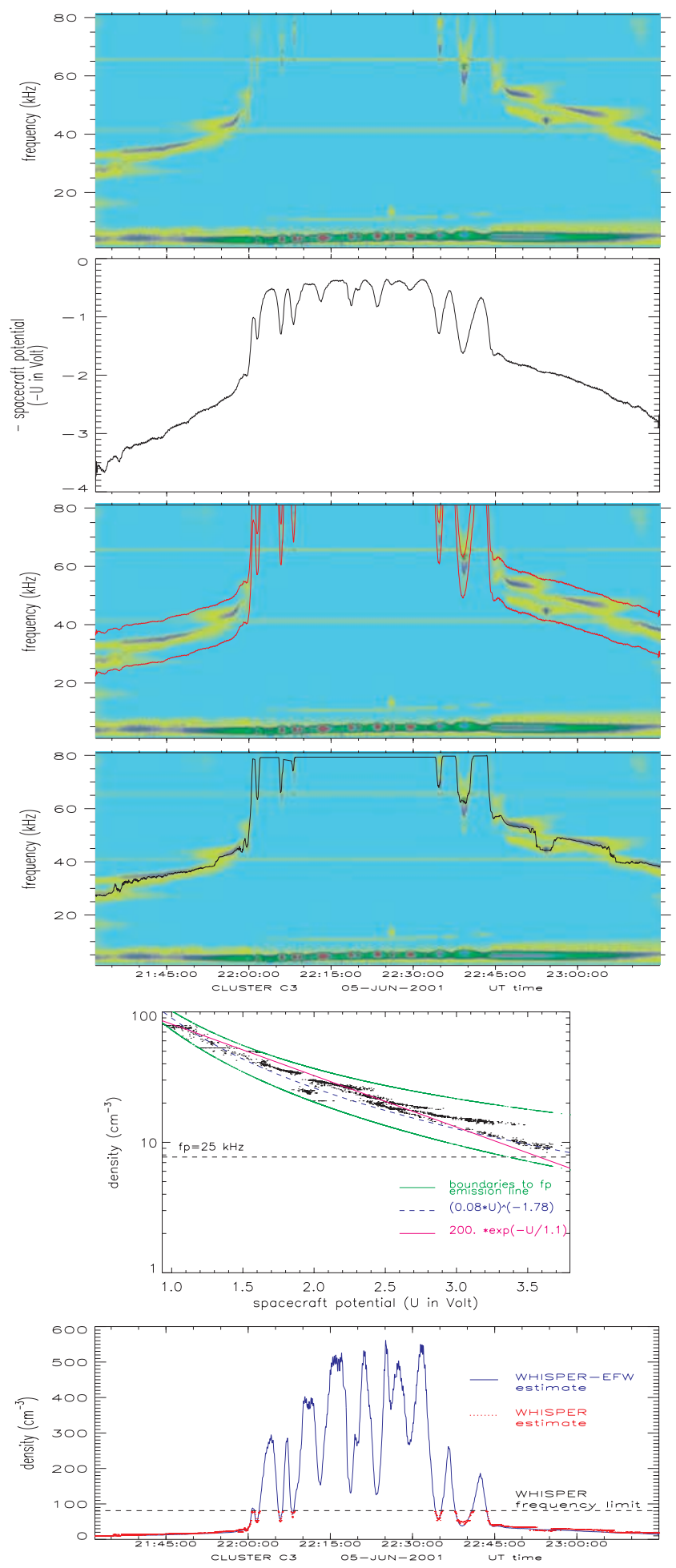

Figure 1. Illustration of the method used to estimate the density. From top to bottom, the panels represent the (a) WHISPER passive electric field spectrogram, (b) EFW spacecraft potential, (c) spectrogram with the emission around $f_{p}$ delimited by two functions of the potential (red lines), (d) spectrogram with deduced $f_{p}$ (black line), (e) resulting "WHISPER density" (below $80 \mathrm{~cm}^{-3}$ ) against EFW potential with best theoretical (solid pink line) and best empirical (dashed purple line) fits, (f) "WHISPER density" (red dotted line) and extrapolated "WHISPEREFW density" (blue solid line).
[6] Prior to describing the wave observation, we show how to estimate the density with CLUSTER data deeper inside the plasmapause. The problem is that the CLUSTER density measurements near perigee are usually limited to the electron density from 0.2 to $80 \mathrm{~cm}^{-3}$, measured by the wave analyser WHISPER. This is because the electron instrument PEACE is turned off (to avoid radiation damage) while the ion instrument CIS is not always operated in the retarding potential analyser mode (necessary to observe cold plasmaspheric ions). We extrapolate the electron density from the spacecraft potential provided by the EFW experiment [Gustafsson et al., 1997] after fitting a relationship between observed plasma frequency (from WHISPER passive mode data) and spacecraft potential.

\section{Electron Density Estimate}

[7] The electric spherical probes on board CLUSTER are artificially biased near the potential of the ambient plasma so that the measured potential difference between probe and satellite is approximately the negative value of the satellite potential with respect to the ambient medium. This potential difference is sampled 5 times per second and is here filtered with a 20 point moving average to eliminate spin dependent variations.

[8] The density method uses the fact that the electron density, $n_{e}$, is related to the spacecraft potential, $U$, and to the plasma frequency $\left(f_{p} \sim 9 \sqrt{n_{e}}\right.$ in $\mathrm{kHz} ; n_{e}$ in $\left.\mathrm{cm}^{-3}\right)$. We describe our method using data from CLUSTER C3 on June 5, 2001 from 21:30 UT to 23:15 UT. The WHISPER passive electric field spectrogram and EFW potential are represented in Figure 1, panels (a) and (b). The method includes four steps. (1) Delimit the local $f_{p}$ emission line on the spectrogram with two empirically chosen functions of the potential; here chosen of the form $9 \sqrt{(a U)^{b}} \pm c$, where $a, b$ and $c$ are constants (Figure 1-c). (2) Extract $f_{p}$ by taking the frequency at the inflexion point in the positive slope of the $f_{p}$ emission peak for each spectrum. See resulting $f_{p}$ line over-plotted on the spectrogram and time-series of "WHISPER density" below $80 \mathrm{~cm}^{-3}$ (Figure 1-d). (3) Investigate the relationship between the WHISPER density and the EFW spacecraft potential. A best fit to the data points (above $8 \mathrm{~cm}^{-3}$ or $f_{p}$ above $25 \mathrm{kHz}$ ) of the form $n_{e}=$ $(a U)^{b}$ is $n_{e}=(0.08 U)^{-1.78}$ (Figure 1-e). (4) Extrapolate the density, "WHISPER-EFW density", for the whole plasmapause crossing from the time-series of the spacecraft potential using the previous relation (Figure 1-f).

[9] We consider that the $f_{p}$ emission consists of natural electron thermal noise composed of Langmuir and upper hybrid modes. Respectively parallel and perpendicular to the background magnetic field, each mode is observed in different proportion as the antenna rotates. The frequency difference between those modes is negligible here even though the plasma is rather strongly magnetized. The plasma frequency is found below the emission peak frequency and could be defined as the lower frequency cut-off of this emission. Undetermined ion thermal noise justifies choosing $f_{p}$ as in step 2 above, which seems to give steadier results in implementation. Other natural resonances occasionally found near $f_{p}$ near the plasmapause, e.g., electrostatic Bernstein modes [Canu et al., 2001], bring in places some uncertainty in the determination of $f_{p}$. With the present 


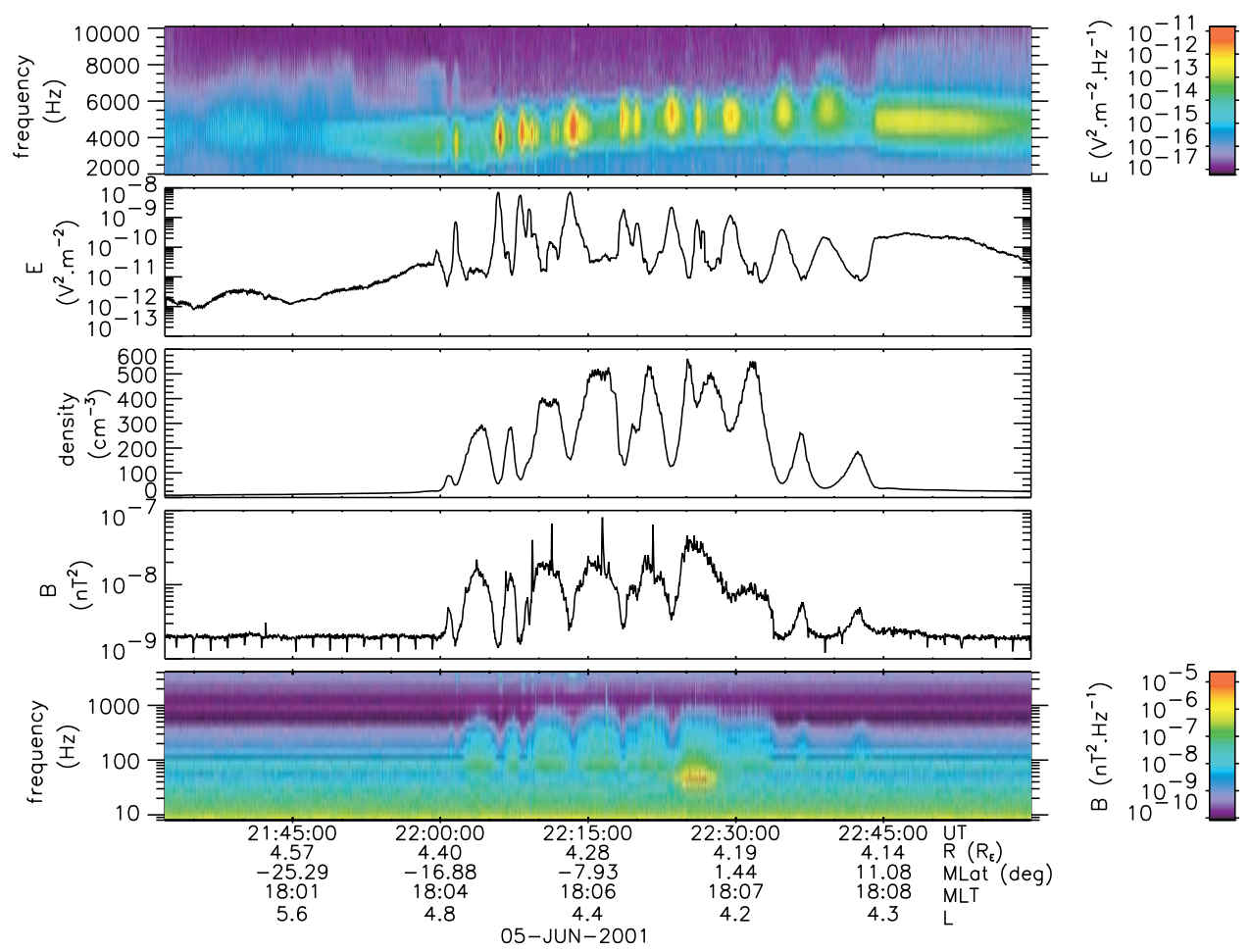

Figure 2. Correlation between whistler mode waves and density. From top to bottom, the panels show the (a) WHISPER electric field spectrogram below $10 \mathrm{kHz}$, (b) WHISPER frequency integrated electric intensity, (c) WHISPER-EFW density estimate, (d) STAFF frequency integrated magnetic intensity, (e) STAFF magnetic field spectrogram.

simple algorithm, the relative uncertainty on $f_{p}$ is below $4 \%$, and twice that for the density.

[10] The relation between electric potential and density depends on the contribution of each type of particles [Laakso and Pedersen, 1998]. For a single electron Maxwellian distribution, the density is proportional to an exponential of the spacecraft potential over the thermal energy of an electron, $n_{e}=n_{0} e^{-U / U_{T}}$; a best fit with this model is obtained for $n_{0}=200 \mathrm{~cm}^{-3}$ and $U_{T}=1.1 \mathrm{eV}$ (Figure 1), which fits well only to a region of the experimental curve (Figure 1).

[11] The range of density attainable with this method is only limited by the condition that the probe potential remains positive. An incursion into negative values would mean a strong dependence of the probe potential upon both electron density and temperature [Laakso and Pedersen, 1998]. In practice despite some shortcomings the method brings a very useful and good quality estimate of $f_{p}$ over a long period of time and is adequate for this study.

\section{Correlation Between the Whistler Mode Waves and Density}

[12] The waves observed by WHISPER C3 on June 5, 2001, from 21:32 UT to 23:15 UT, occupy a $2 \mathrm{kHz}$ wide frequency band in the range of $3-6 \mathrm{kHz}$ (Figure 1 and detail in Figure 2), approximately $0.4<f / f_{c_{e}}<0.6$. Their electromagnetic nature is revealed by complementary evidence from STAFF magnetic wave field data near the instrument's frequency limit (Figure 2). Hence the waves are likely whistlers according to the cold plasma classifica- tion. The electron cyclotron frequency appears as a resonance line in the active spectra but in this case is also visible as a natural electron cyclotron emission line in the passive spectra, around $12 \mathrm{kHz}$ with a $0.5 \mathrm{kHz}$ bandwidth (Figure 1). The waves central frequency has an opposite curvature to the $f_{c_{e}}$ line, hence $f$ is not proportional to the local $f_{c_{e}}$. The waves in the $3-6 \mathrm{kHz}$ band appear to be modulated by the density fluctuations, their intensity being anticorrelated with the density (Figure 2). Where the density varies from 40 to $190 \mathrm{~cm}^{3}$ the integrated electric field intensity changes from $1.42 \times 10^{-5}$ to $2.7 \times$ $10^{-6} \mathrm{~V} / \mathrm{m}$.

[13] A lower frequency whistler emission band is seen in STAFF electric and magnetic field data during the same time period with a frequency $\sim 100-600 \mathrm{~Hz}$ (Figure 2). The waves are found to be plane polarized, and right hand polarized in the observed frame; polarisation evidence is obtainable with STAFF multicomponent data. On contrary to the waves observed by WHISPER the intensity of this wave band is positively correlated with the density fluctuations (Figure 2). For the example density fluctuation above the integrated magnetic field intensity changes from $4.5 \times$ $10^{5}$ to $6.6 \times 10^{5} \mathrm{nT}$.

\section{Discussion}

[14] The density estimate method should be useful when studying the plasmapause density profiles and fluctuations (or even to provide a density estimate in the Earth's bow shock transition). What is new here is the direct use of a potential-density relationship to deduce a continuous 
extrapolated density above the density limit imposed by the wave data. The theoretical fit for $n_{e}(U)$, although a worst fit than the empirical, gives a reasonable value for the ambient electron temperature. Also, the step of encompassing the $f_{p}$ emission using the spacecraft potential can assist the automatic determination of the plasma frequency from the resonance sounder data.

[15] Key future studies with the CLUSTER spacecraft should concern wave propagation or spatio-temporal determination of the nature of the density enhancements. Threedimensional ray tracing using STAFF data and analysis of the dispersed whistler signatures in WBD data are being carried out. Wave propagation analysis with WHISPER on board individual satellite is limited to fading effects associated with a spining antenna. Multi-point analysis with the four satellites should hopefully bring new insights.

[16] The density modulation of the wave intensity may be the consequence of propagation through the large density structures. The $100-600 \mathrm{~Hz}$ emission band is positively correlated to the density and disappears in the troughs so that the interpretation of ducting in density enhancements holds well [Koons, 1989]. The whistler mode emission band at $3-6 \mathrm{kHz}$ is anticorrelated to the density, and disappears in the peaks although the figure suggest a more continuous modulation, noise level is reached. This suggests trough ducting for these whistlers.

[17] The 3-6 kHz waves is observed during the whole plasmapause and outer plasmasphere crossing, and could well be generated near or at the plasmapause and propagate back and forth within it. The plasmapause was shown to be an effective guide to VLF whistler mode energy with larger density gradient increasing guidance efficiency [Inan and Bell, 1977] and "trough trapping" could explain higher concentration in density troughs. There is also enhanced $f_{p}$ emission in the trough of the density fluctuations, suggesting the possibility of a radio emission wave-wave mechanisms taking place [Jones, 1982].

[18] Acknowledgments. We are grateful to the CLUSTER instruments, operations, and software teams. OM thanks the Astronomy Unit at Queen Mary in London for hosting him during the revision of this paper.

\section{References}

Angerami, J. J., Whistler duct properties deduced from VLF observations made with the OGO 3 satellite near the magnetic equator, J. Geophys. Res., 75, 6115-6135, 1970.

Canu, P., et al., Identification of natural plasma emissions observed close to the plasmapause by the Cluster-Whisper relaxation sounder, Annales Geophysicae, 19(Oct.), 1697-1709, 2001.

Carpenter, D. L., B. L. Giles, C. R. Chappell, P. M. E. Décréau, R. R. Anderson, A. M. Persoon, A. J. Smith, Y. Corcuff, and P. Canu, Plasmasphere dynamics in the duskside bulge region: A new look at old topic, J. Geophys. Res., 98, 19,243-19,271, 1993.

Carpenter, D. L., and J. Lemaire, Erosion and Recovery of the Plasmasphere in the Plasmapause Region, Space Science Reviews, 80, 153-179, 1997.

Cornilleau-Wehrlin, N., et al., The Cluster Spatio-Temporal Analysis of Field Fluctuations (STAFF) Experiment, Space Science Reviews, 79, 107-136, 1997.

Décréau, P. M. E., et al., Whisper, a Resonance Sounder and Wave Analyser: Performances and Perspectives for the Cluster Mission, Space Science Reviews, 79, 157-193, 1997.

Gurnett, D. A., R. L. Huff, and D. L. Kirchner, The Wide-Band Plasma Wave Investigation, Space Sci. Rev., 79, 195-208, 1997.

Gustafsson, G., et al., The Electric Field and Wave Experiment for the Cluster Mission, Space Science Reviews, 79, 137-156, 1997.

Inan, U. S., and T. F. Bell, The plasmapause as a VLF wave guide, J. Geophys. Res., 82, 2819-2827, 1977.

Jones, D., Terrestrial Myriametric radiation from the Earth's magnetopause, Planet. Space Sci., 30, 399-410, 1982.

Koons, H. C., Observations of large-amplitude, whistler mode wave ducts in the outer plasmasphere, J. Geophys. Res., 94, 15,393-15,397, 1989.

Laakso, H., and A. Pedersen, Ambient electron density derived from differential potential measurements, in Measurement Techniques in Space Plasmas, edited by J. Borovsky, R. Pfaff, and D. Young, AGU Monograph 102, pp. 49-54, AGU, Washington, D.C., 1998.

Lemaire, J. F., and K. I. Gringauz, The Earth's plasmasphere, Cambridge Univ. Press, Cambridge, 1998.

Sonwalkar, V. S., R. A. Helliwell, and U. S. Inan, Wideband VLF electromagnetic bursts observed on the DE-1 satellite, Geophys. Res. Lett., 17, $1861-1864,1990$.

O. Moullard, A. Masson, and H. Laakso, Research and Scientific Support Department, ESTEC, ESA, Keplerlaan 1, 2201 AZ Noordwijk, Netherlands. (om@rssd.esa.int; amasson@rssd.esa.int; hlaakso@rssd.esa.int)

M. Parrot and P. Décréau, LPCE, 3A Avenue de la Recherche Scientifique, 45071 Orléans Cedex 2, France. (mparrot@cnrs-orleans.fr; pdecreau@cnrs-orleans.fr)

O. Santolik, MFF, Charles University, V Holesovickach 2, CZ-18000 Praha 8, Czech Republic. (ondrej.santolik@mff.cuni.cz)

M. Andre, Swedish Institute of Space, Uppsala Division, Box 537, Uppsala, 75121 Sweden. (Mats.Andre@irfu.se) 